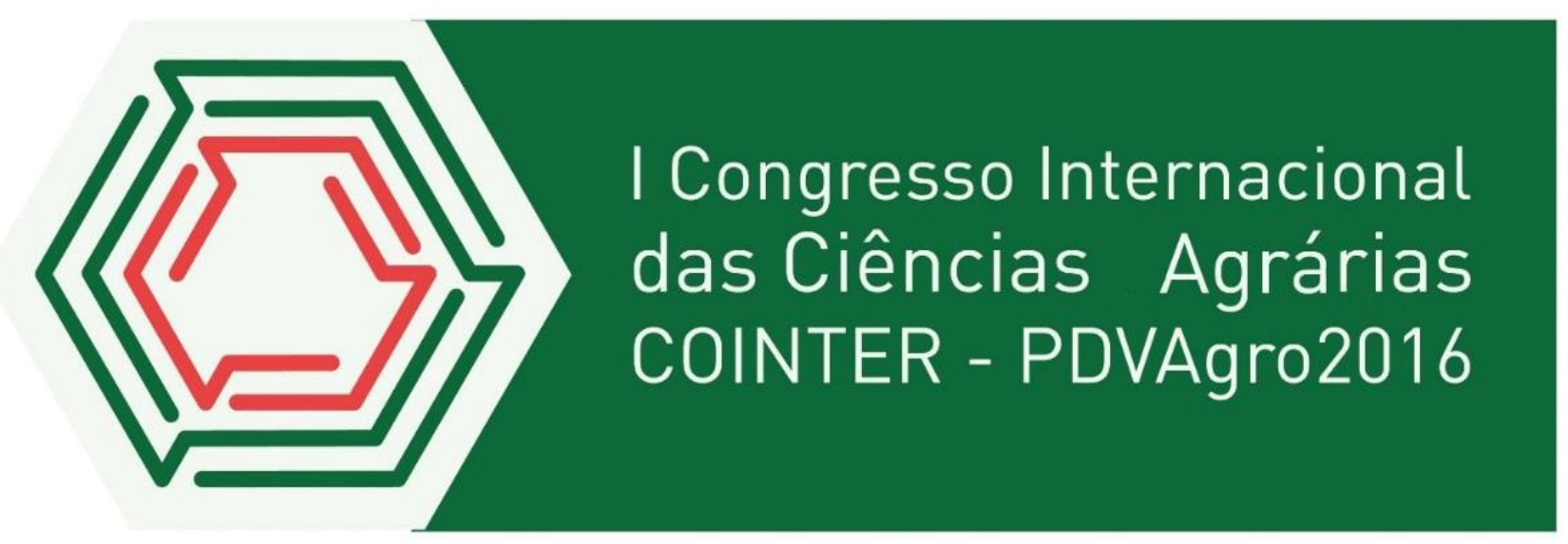

\title{
CARACTERIZAÇÃO FÍSICO-QUÍMICA E SENSORIAL DE GELADO COMESTÍVEL ELABORADO COM POLPA DO FRUTO DE MANDACARU ADICIONADO DE SORO DE LEITE
}

\author{
Apresentação: Pôster \\ Tâmara Rafaela da Silva*; Carolaine Gomes dos Reis ${ }^{1}$; Jânio E. de Araújo Alves²; Cristiane \\ Ayala de Oliveira ${ }^{3}$
}

\section{Introdução}

Segundo a RDC $\mathrm{n}^{\circ} 276$, de 25 de setembro de 2003, define-se gelados comestíveis como produtos alimentícios obtidos a partir de uma emulsão de gorduras e proteínas, com ou sem a adição de outros ingredientes e substâncias, ou de uma mistura de água, açúcares e outros ingredientes e substâncias que tenham sido submetidas ao congelamento, em condições que garantam a conservação do produto no estado congelado ou parcialmente congelado, durante o armazenamento, o transporte, a comercialização e a entrega ao consumo.

O mandacaru (Cereus jamacaru P.C) é uma espécie nativa da vegetação da caatinga, pertencendo à família Cactácea. Cresce em solos pedregosos e junto a outras espécies de cactáceas, forma a paisagem típica da região Semiárida do Nordeste, sendo encontrado nos Estados do Piauí, Ceará, Rio Grande do Norte, Paraíba, Pernambuco, Alagoas, Sergipe, Bahia e norte de Minas Gerais (SILVA; ALVES, 2009). Seu fruto possui polpa branca com sementes pretas. É muito utilizado como alimentos para os animais.

O soro de queijo é um subproduto bastante proteico que gera dores de cabeça para as indústrias, por conta da sua alta carga poluente. O mesmo é utilizado em algumas bebidas lácteas 
agregando valor nutricional. A elaboração de um produto tipicamente brasileiro, aproveitando um fruto pouco utilizado na alimentação humana, aliado a um subproduto bastante proteico, reduzindo uma grande carga poluente, é de suma importância. O presente estudo teve como objetivo avaliar as características físico-químicas e sensoriais do gelado comestível da polpa do fruto do mandacaru adicionado de soro de queijo.

\section{Fundamentação Teórica}

Atualmente, o mercado brasileiro de sorvetes está dividido entre os produtos industrializados e os fabricados em escala artesanal (SILVA et al. 2006. O Nordeste brasileiro destaca-se como um grande produtor de frutos tropicais nativos e cultivados, em virtude das condições climáticas prevalecentes. A fruticultura, nesta região, constitui-se em atividade econômica bastante promissora, devido ao sabor e aroma exótico de seus frutos e à sua enorme diversificação. O conhecimento do valor nutritivo desses frutos assume importância considerável, pois alimentação adequada e aplicação de métodos tecnológicos eficientes só se tornam possíveis mediante conhecimento do valor nutricional dos alimentos (NORONHA et al. 2000).

O soro de leite representa de 80 a $90 \%$ do volume total do leite utilizado durante a produção de queijos e contém, aproximadamente, 55\% dos nutrientes do leite: proteínas solúveis, lactose, vitaminas, minerais e uma quantidade mínima de gordura (ALVES, MOREIRA, JÚNIOR, MARTINS, PERRONE, CARVALHO, 2014). Se jogados diretamente nos rios podem causar contaminação, além de gerar problemas ambientais na fauna e na flora, uma vez que as bactérias presentes na água do rio irão se multiplicarem em alta velocidade consumindo o oxigênio dissolvido, então as algas (fitoplâncton) e pequenos animais (zooplâncton) morrem pela falta de oxigênio, consequentemente o alimento disponível para larvas e pequenos peixes irá se reduzir continuamente até que o rio morra (CORTEZ, 2013).

\section{Metodologia}

O presente estudo, descritivo e experimental, foi desenvolvido no Laboratório de Tecnologia de Produtos de Origem Vegetal do Instituto Federal de Educação, Ciências e Tecnologia do Sertão Pernambucano campus Salgueiro, PE. Para a elaboração do sorvete utilizou-se a polpa do fruto do mandacaru (Cereus jamacaru P.C) com adição de soro de queijo. A fim de avaliar as características físico-químicas e sensoriais do mesmo. 


\section{Resultados e Discussões}

Foram elaboradas duas formulações do sorvete, com leite integral (F1) e a outra com soro do leite (F2), as duas formulações avaliaram-se sensorialmente com comparativo a um sorvete de creme adquirido no comercio local. Foram 60 provadores não treinados, alunos e servidores do campus, avaliando os seguintes aspectos: cor, sabor, textura e aparência através da escala hedônica estruturada de 9 pontos, indicando a amostra preferida, como mostra na tabela1.

Tabela1. Média das notas dos testes de aceitação. Fonte: Própria

\begin{tabular}{|c|c|c|c|c|c|}
\hline & Aparência & Aroma & Textura & Sabor & $\begin{array}{c}\text { Impressão } \\
\text { Global }\end{array}$ \\
\hline Controle & $8,21^{\mathrm{c}}$ & $8,13^{\mathrm{b}}$ & $8,15^{\mathrm{c}}$ & $8,11^{\mathrm{c}}$ & $8,06^{\mathrm{c}}$ \\
\hline $\begin{array}{c}\text { Sorvete } \\
\text { Soro }\end{array}$ & $6,03^{\mathrm{a}}$ & $6,15^{\mathrm{a}}$ & $5,94^{\mathrm{a}}$ & $6,13^{\mathrm{a}}$ & $6,23^{\mathrm{a}}$ \\
\hline $\begin{array}{c}\text { Sorvete } \\
\text { Leite }\end{array}$ & $7,05^{\mathrm{b}}$ & $6,81^{\mathrm{a}}$ & $6,75^{\mathrm{b}}$ & $6,96^{\mathrm{b}}$ & $7,00^{\mathrm{b}}$ \\
\hline
\end{tabular}

a-c: letras iguais na mesma coluna diferem entre si a um nível de 5\% de significância pelo teste de tukey

Observando-se a tabela 1, percebe-se que as amostra controle foi a que obteve maiores notas em todos os aspectos avaliados, enquanto as outras duas formulações apresentam índices razoáveis de aceitação. Relacionado ao sabor do sorvete soro, a sua nota razoável deve-se ao acentuado sabor salgado. Os provadores avaliaram também a intenção de compra das formulações. Um ótimo índice de aceitabilidade é maior ou igual a 70\%. Nota-se que a amostra elaborada com leite foi a que se aproximou do índice de $70 \%$. Como mostra a tabela 2.

Tabela 2. Índice de aceitabilidade e intenção de compra. Fonte: Própria

\begin{tabular}{|c|c|c|}
\hline $\begin{array}{c}\text { Amostra } \\
\mathrm{s}\end{array}$ & Intenção de compra & $\begin{array}{c}\text { Índice de } \\
\text { Aceitabilidade }(\%)\end{array}$ \\
\hline Controle & 4,8 & 96 \\
\hline Soro & 2,9 & 58 \\
\hline Leite & 3,4 & 68 \\
\hline
\end{tabular}

As avaliações físico-químicas de acidez, umidade, cinzas, sólidos totais, gordura, carboidratos, proteínas e $\mathrm{pH}$ foram realizadas de acordo com as Normas Analíticas do Instituto Adolfo Lutz (2005). A análise de cor objetiva foi realizada através do calorímetro WAVE, onde foram avaliados os parâmetros de $\mathrm{L}^{*}$ (Luminosidade), $\mathrm{a}^{*}$ (direção para o vermelho) e $\mathrm{b}^{*}$ (direção para o azul). Todas as análises foram realizadas em triplicata e as médias foram comparadas através do teste de Tukey a um nível de 5\% de significância, sendo analisados por meio do programa 
estatístico ASSISTAT versão 7.7, 2014 (SILVA, 2014). Resultados na tabela 3.

Tabela 3. Caracterização do sorvete de mandacaru utilizando leite e soro de leite. Fonte: Própria

\begin{tabular}{|c|c|c|}
\hline Variáveis & Leite & Soro \\
\hline Umidade & $75,47 \pm 0,46^{\mathrm{a}}$ & $73,41 \pm 0,35^{\mathrm{b}}$ \\
\hline Proteína & $2,75 \pm 0,15 \mathrm{~b}$ & $3,18 \pm 0,09^{\mathrm{a}}$ \\
\hline Gordura & $5,74 \pm 0,16^{\mathrm{a}}$ & $4,35 \pm 0,28^{\mathrm{b}}$ \\
\hline Cinzas & $0,56 \pm 0,06^{\mathrm{b}}$ & $0,91 \pm 0,01^{\mathrm{a}}$ \\
\hline Carboidratos & $15,45 \pm 0,64^{\mathrm{b}}$ & $18,12 \pm 0,62^{\mathrm{a}}$ \\
\hline $\mathrm{pH}$ & $6,06 \pm 0,02^{\mathrm{b}}$ & $5,96 \pm 0,02^{\mathrm{b}}$ \\
\hline ATT & $0,32 \pm 0,04^{\mathrm{a}}$ & $0,23 \pm 0,06^{\mathrm{a}}$ \\
\hline SST $^{\circ}($ BRIX) & $29,0 \pm 0,00^{\mathrm{a}}$ & $25,66 \pm 0,57^{\mathrm{b}}$ \\
\hline $\mathrm{L}^{*}$ & $82,92 \pm 4,89^{\mathrm{a}}$ & $77,80 \pm 2,82^{\mathrm{a}}$ \\
\hline $\mathrm{A}^{*}$ & $-0,67 \pm 0,07^{\mathrm{a}}$ & $-0,37 \pm 0,16^{\mathrm{b}}$ \\
\hline $\mathrm{B}^{*}$ & $9,58 \pm 0,21^{\mathrm{a}}$ & $7,27 \pm 0,49^{\mathrm{b}}$ \\
\hline
\end{tabular}

a-b: Letras diferentes na mesma linha, diferem estatisticamente entre si a um nível de $5 \%$ de significância $(\mathrm{p}<0,05)$ pelo teste de Tukey.

O conteúdo de proteínas para o sorvete elaborado com soro de queijo diferiu estatisticamente $(\mathrm{p}<0,05)$ da formulação elaborada apenas com leite, apresentando valores superiores, tal resultado pode ser explicado pelo alto conteúdo de proteínas existente no soro, que podem ter afetado diretamente o conteúdo do produto final.

\section{Conclusões}

Com a realização deste estudo, conclui-se que a polpa do fruto do mandacaru para a elaboração do gelado comestível é uma alternativa viável, tanto economicamente para as indústrias, para os moradores, como também a minimização do impacto ambiental causado pelo soro do queijo bem como o aproveitamento do fruto. O percentual de aceitabilidade do produto na formulação leite integral (F1) apresentou maior aceitação quando comparado a formulação que utiliza o soro (F2), necessitando-se de mais estudos, a fim de se obter uma maior aceitação em relação ao sorvete comercial.

\section{Referências}

ALVES, M.P; MOREIRA, R.O; JÚNIOR, P.H.R; MARTINS, M.C.F; PERRONE, I.T; CARVALHO, A.F. Soro de leite: Tecnologias para o processamento de coprodutos. Rev. Inst. Laticínios Cândido Tostes, Juiz de Fora, v.69, n.3, p. 212-2216, mai/jun,214. 
CORTEZ, N. M. S. Diagnóstico da produção do soro de queijo no estado do Rio de Janeiro. 2013. Tese (Doutorado em Medicina Veterinária) - Universidade Federal Fluminense, Niterói, 2013.

NORONHA, M. A. S.; CARDOSO E. de A.; DIAS N. da S. Características físico-químicas de frutos de umbu-cajá spondias sp . provenientes dos pólos Baixo-Jaguaribe (ce) e Assu-Mossoró (RN). Revista Brasileira de Produtos Agroindustriais, Campina Grande, v.2, n.2, p.91-96, 2000.

Resolução RDC n 267, de 25 de setembro de 2003.

SILVA, L. R. da; ALVES, R. E. Caracterização físico-química de frutos de "Mandacaru". Rev. Acad., Ciênc. Agrár. Ambient., Curitiba, v. 7, n. 2, p. 199-205, abr./jun. 2009.

SILVA, K.; BOLINI, H. M. A. Avaliação sensorial de sorvete formulado com produto de soro ácido de leite bovino. Ciênc. Tecnol. Alim., v. 1, n. 26, p. 116-122, 2006. 